\title{
Acquisition and retention of dark avoidance by the toad, Xenopus laevis (Daudin)
}

\author{
ILAN KARPLUS, DANIEL ALGOM, and DAVID SAMUEL \\ Department of Isotope Research, Weizmann Institute of Science, Rechovot, Israel
}

\begin{abstract}
Young toads, Xenopus laevis, were trained for dark avoidance in a passive avoidance paradigm using electric shock in a fully automatic training and recording procedure. Dark avoidance was acquired within approximately $30 \mathrm{~min}$ and was retained on retesting $24 \mathrm{~h}$ later. Comparison of the performance of the toads during training and during retesting was used as an indicator for saving or reinforced retention. Control experiments demonstrated that changes in behavior were due to learning and not to nonassociative effects such as pseudoconditioning, increased sensitization to shock, or acquaintance with the testing apparatus.
\end{abstract}

Our knowledge of learning and memory processes in amphibians, and especially in anura, is scarce. This scarcity is not the result of these groups' being overlooked. On the contrary, the amphibians, both as an important link between fish and higher vertebrates and as common, much used laboratory animals, have attracted much attention with respect to learning, albeit with little success. The reasons for this are: difficulties in training anura (frogs and toads) due to their overall low activity rate (Boice, Quanty, \& Williams, 1974), their unstable rate of responding (Thorpe, 1963), and their reluctance to engage in instrumental learning situations. For these reasons, toads and frogs have had to be prodded to make them respond (Williams, 1967) or given footshocks (Greding, 1971) before training could begin. Many different methods of training have been tried, including labyrinths (Yerkes, 1903), T-mazes (Chu \& McCain, 1969; Haubrich, 1966; Williams, 1967), one-way avoidance boxes (Crawford \& Longdon, 1966; Miller, Berk, \& Springer, 1974), and shuttleboxes (McGill, 1960). The training in each case required repetitive manual manipulations of the animals with many sessions, often lasting several days (Crawford \& Longdon, 1966; Haubrich, 1966). In many reports, adequate controls are lacking and many of the subjects died during the training process (Thompson \& Boice, 1975). An automatic training procedure for toads was developed by Miller and Berk (1977), but it had the disadvantages of being based on the continuous administration of an electric current during the entire duration of the training $(24 \mathrm{~h})$ and of lacking an automatic recording device.

We wish to describe the use of a fully automatic and reliable training procedure for Xenopus laevis.

We wish to thank I. Sher for his excellent technical assistance. This study was supported by a grant from the Israel Center for Psychobiology, Charles E. Smith Family Foundation.
This toad is of particular interest as a research subject, since it has been used extensively by physiologists, neuroanatomists, and biochemists. As a species that has been successfully cloned (Elsdale, Gurdon, \& Fischberg, 1960), it is a potential subject for many innovative psychological studies. This procedure enables one to assess the learning and retention characteristics of anura more reliably, thus allowing comparison with other species and different learning situations.

\section{METHODS}

\section{Subjects}

Forty-six young, naive Xenopus laevis (Daudin), with a mean body length (nose to anus) of $33.7 \pm 1.56 \mathrm{~mm}$ (SD) served as subjects. The toads were raised from eggs in aquaria equipped with an air supply and filters. After metamorphosis, the toads were transferred to white water-filled plastic trays and were fed three times a week on fly larvae. Both tadpoles and toads were kept under continuous fluorescent light illumination at a temperature of $20^{\circ}$. $24^{\circ} \mathrm{C}$.

\section{Apparatus}

The training apparatus was a "square" track with rounded corners (Figure 1). The rounded corners facilitated the smooth movement of the subjects around the track and precluded their being trapped in a corner. The purpose of the "square" shape of the track was to slow down the animal's movement. This track consisted of a Perspex floor and lid and four external and internal walls. The length of the internal walls was $8 \mathrm{~cm}$, and the length of the external wall, $15 \mathrm{~cm}$. Two horizontal stainless steel wires were affixed along the whole length of both internal and external walls of the track, which was filled to a depth of $2 \mathrm{~cm}$ with untreated tap water. One quarter of the track had transparent walls and lid and a white floor, while the rest of the track was blackened on all sides, including the lid, in order to exclude direct light. Removable transparent partitions were placed between the light and dark areas. When the toad moved from the lighted area into the darkened area, it triggered, through a photoelectric device, a train of electric shock pulses (10-V ac, $2-\mathrm{sec}$ shock per $3 \mathrm{sec})$. When the toad moved out of the dark area, the shock ceased automatically. The position of the toad was monitored with an Esterline Angus recorder operated by the same photoelectric control system. A similar principle has been used for the training of urodeles (tailed 


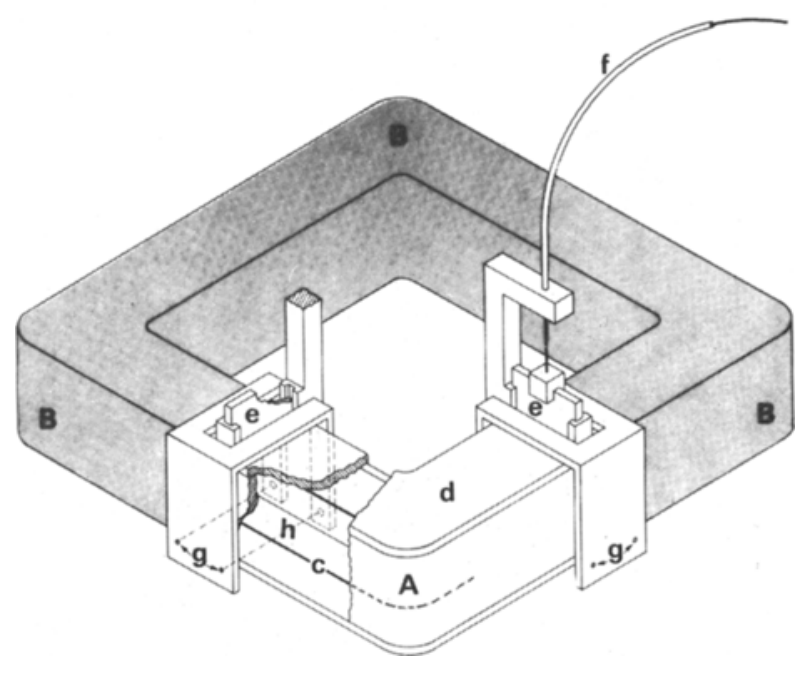

Figure 1. Apparatus for training toads for a dark avoidance. A, transparent part of apparatus; B, blackened part of apparatus; C, steel wires; D, transparent lid; E, removable transparent partitions; F, device for lifting partitions; $G$, photo cell; and $H$, light beam.

amphibians) in a dark-avoidance paradigm in this laboratory (Hershkowitz, Segal, \& Samuel, 1972). The apparatus was shielded from all sides in order to avoid external disturbances. Observations were made from time to time through an oblique mirror. Simple, remote-control push-pull rods were used to open and shut the partitions.

\section{Procedure}

Twenty-four hours prior to training, all the toads were kept in isolation in glass-covered yellow plastic boxes $(20 \times 10 \times 10 \mathrm{~cm})$ filled to a depth of $4 \mathrm{~cm}$ with tap water under constant fluorescent illumination at a temperature of $22^{\circ} \pm 1^{\circ} \mathrm{C}$. During training, each toad was placed in the light area of the apparatus by means of a small hand-net. One minute later, the transparent partitions were removed and the toad was allowed to enter the dark area, which it did preferentially (see Discussion). One hour after the start of the experiment, the toad was removed from the apparatus and returned to its box. All training experiments were carried out in a temperature of $22^{\circ} \pm .5^{\circ} \mathrm{C}$ between 10:00 a.m. and 4:00 p.m. The toads were always introduced twice into the apparatus. In some experiments, the toads were treated similarly during the first and second training sessions, and in others they received different treatments.

Four separate training experiments were carried out. In Experiment 1 , young adult Xenopus laevis toads $(\mathrm{n}=10)$ were trained to avoid the dark by being shocked whenever they entered the dark; $24 \mathrm{~h}$ later, the same paradigm was repeated. In Experiment 2, young adult toads $(n=10)$ were trained to avoid the dark, as in Experiment 1; the interval between training and testing was increased to $48 \mathrm{~h}$. In Experiment 3, young adult toads $(n=8)$ did not receive any electric shock during the first session; $24 \mathrm{~h}$ later, they received electric shock whenever they entered the dark area. Experiment 4 included nine pairs of toads and two identical training apparatuses. Each pair consisted of a randomly selected to-betrained toad and its yoked control. In the first training session, the trained toad received electric shocks whenever it entered the dark, while the yoked control received the same shock at the same time independent of its position. Twenty-four hours later, during the second session (testing), both the trained toad and the yoked control received electric shock contingent upon their behavior.

\section{RESULTS}

The results of the first experiment (Figure 2) show that there was a marked reduction in total time spent in the dark during blocks of training, both in the first (acquisition) session and $24 \mathrm{~h}$ later during the retention session. These changes are statistically significant, as revealed by a repeated-measure ANOVA (Days by Blocks) $[F(5,45)=18.9, p<.01]$. The same analysis also reveals a significant difference between acquisition and retention $[F(1,9)=7.8, p<.005]$, at least in the first block $[\mathrm{t}(9)=3.33, \mathrm{p}<.01]$. While performance improved significantly during both training sessions, the rate at which this improvement occurred was different, as indicated by a significant interaction between blocks and days $[F(5,45)=5.76$, $\mathrm{p}<.01]$. A direct comparison of the slopes of the learning curves over the first three blocks (first $30 \mathrm{~min}$ ) during the first and second days revealed a significant difference $[t(9)=2.525, p<.05]$. Direct observations also showed a change in the behavior of the toad when approaching the dark areas. Although, at the start of the training session, the toad entered the dark areas readily, later it would approach the dark slowly and cautiously, sometimes turning around and moving out again before completely entering the dark and before receiving the electric shock.

The results of Experiment 2 (Figure 3) were analyzed by a repeated-measure ANOVA (Blocks by Days). The only significant effect was that of blocks of training $[F(5,45)=10.75, p<.01]$, indicating a similar significant improvement in performance on both days. Neither days nor the interaction were significant (both Fs $<1$ ). These results indicate that no savings of dark avoidance occurred when the sessions were separated by $48 \mathrm{~h}$.

The results of Experiment 3 (Figure 4) show that during the first session the toads spent almost all

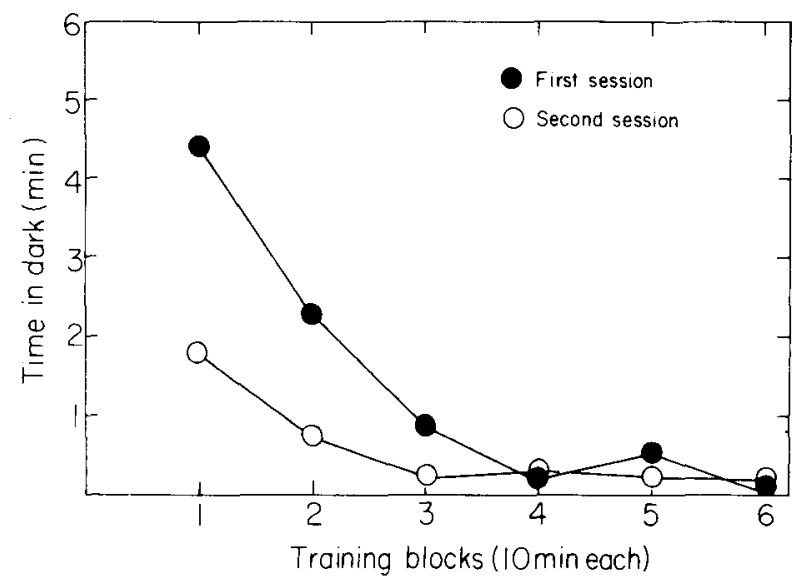

Figure 2. Experiment $1(n=10)$. Time spent in dark as a function of blocks of training ( $10 \mathrm{~min}$ each) during two training sessessions. Twenty-four-hour time interval between training sessions. 


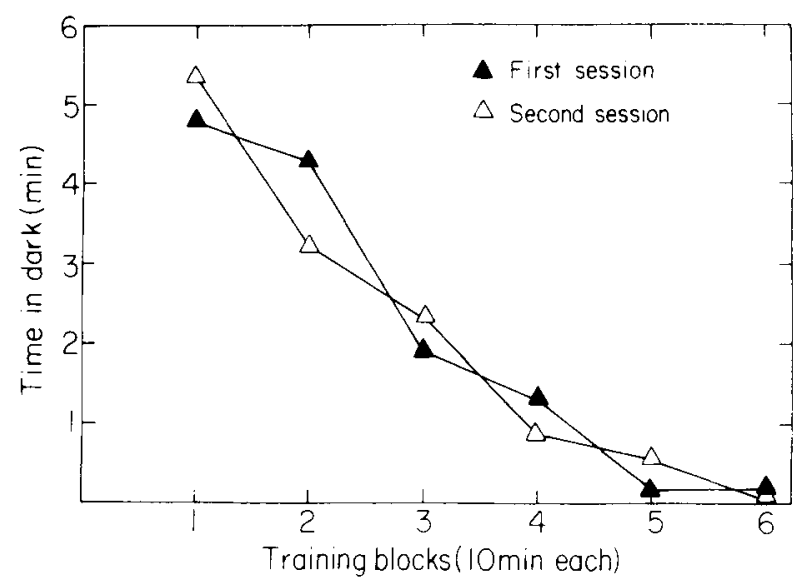

Figure 3. Experiment $2(n=10)$. Time spent in dark as a function of blocks of training ( $10 \mathrm{~min}$ each) during two training sessions. Forty-eight-hour time interval between sessions.

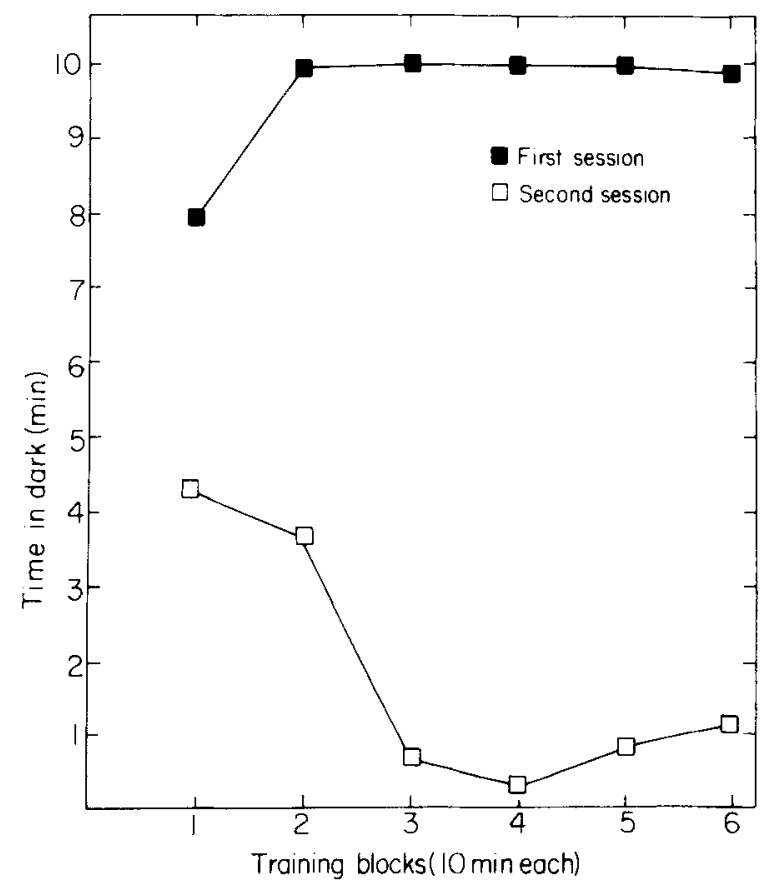

Figure 4. Experiment $3(n=8)$. Time spent in dark as a function of blocks of training ( $10 \mathrm{~min}$ each) during two training sessions. Twenty-four-hour time interval between training sessions, first session without electric shock, second session with contingent shock.

their time in the dark. In the second session, the usual learning curve, due to the shock contingency, was obtained. The two curves differ from one another, as shown by inspection and by repeated-measures ANOVA (Blocks by Days) $[F(5,35)=2.912, p<.05 ; F(1,7)=$ $5.618, p<.001$; and $F(5,35)=13.57, p<.01]$, for blocks, days, and their interaction, respectively].

The statistical analyses of Experiment 4 (Figure 5) were first made for the two groups separately. Both training sessions of the first group yielded the usual learning curves, albeit differing in some parameters. A repeated-measure ANOVA revealed significant differences in performance as a function of blocks of training during both sessions $[\mathrm{F}(5,40)=10.22$, $\mathrm{p}<$ $.01]$, a significant difference between days $[F(1,8)=$ $7.804, \mathrm{p}<.05$ ], and a significant interaction term $[F(5,40)=2.758, p<.05]$. The overall performance of this group resembles that of the subjects of Experiment 1 .

The same analysis was performed on the second group of subjects of Experiment 4. As might be expected, the curves from the first and the second sessions differed markedly $[\mathrm{F}(5,40)=3.09, \mathrm{p}<.05$; $F(1,3)=31.8, p<.01 ; F<1$, for blocks, days, and their interaction, respectively]. In the first session, yoked toads spent most of their time in the dark; only when the contingent shock schedule was used was there a gradual reduction of time spent in the dark.

Experiments 3 and 4 served as controls for the elimination of nonassociative effects on performance. Experiment 3 was run in order to assess the effect of familiarity with the testing apparatus on the learning process. Comparing performance in the second session of Experiment 3 with performance in the first session of Experiment 1, no significant differences whatsoever were found between the respective curves. Thus, prior acquaintance with the apparatus had no effect on the learning processes, eliminating explanations of savings due to mere prior exposure to the apparatus.

The purpose of Experiment 4 was to serve as a control for the other nonassociative effects. The performance of the yoked control group receiving noncontingent reinforcement can be presumed to be due to either such factors as sensitization or pseudoconditioning. The comparison between the performance of the "yoked" group on their second training session and the performance of the regular shock-contingent group on their first training session reveals no significant difference in slope or in time spent in the dark during the first blocks $($ ts $<1)$. These results indicate the lack of any significant effect on performance due to the exposure of subjects to noncontingent electric shocks which could result in sensitization, altered reactivity to the electric current, etc. We may conclude, therefore, that the improvement in performance during the contingent sessions was due to associative factors.

In addition to the specific aims of the four experiments, and assuming the lack of any intervention of nonassociative factors, five repetitions of the basic acquisition schedule by different subjects were run (Eperiment 1, first session; Experiment 2, first session; Experiment 3, second session; Experiment 4, first group, first session, and yoked group, second 


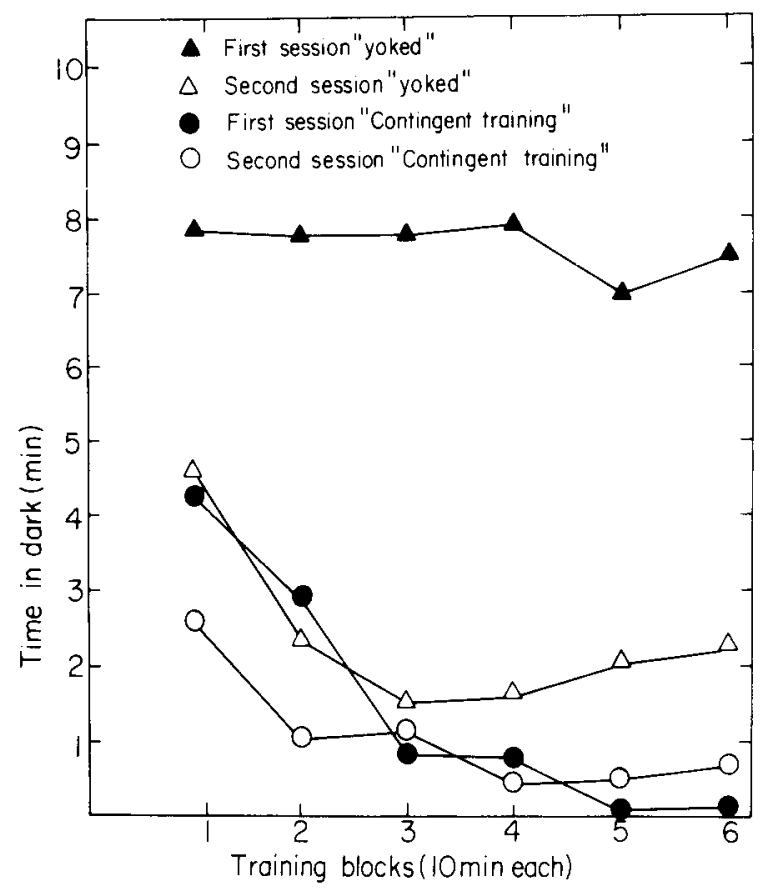

Figure 5. Experiment $4(n=18)$. Time spent in dark as a function of blocks of training during two training sessions. During the second session, the "yoked" group receives contingent shocks (see text for further details).

session). Therefore, one might expect that the differences in performance between the various groups of subjects should not exceed random fluctuations. A statistical analysis revealed that, indeed, no significant differences between the parameters of the learning curves of these five groups occurred for slope and for time spent during the first block, $\mathrm{F}<1$; for time spent during the last three blocks, $F(4,41)=2.336, p>.05$.

\section{DISCUSSION}

The main difficulty in training toads and frogs is the behavioral passivity many of these species demonstrate in arbitrary laboratory settings. These difficulties can be treated by using several nonexclusive strategies. Perhaps the most direct way is to begin to choose learning paradigms by observing what the animals learn in nature (Rosenkoetter \& Boice, 1975). Such observations suggest that frogs and toads are successful in learning where to find food, where to find hiding places, and where to find mates. Selective use of these responses for appropriate subjects should yield satisfactory performance in learning situations. Boice (1970) has demonstrated successful acquisition and retention of an active avoidance task by active species of toads and the lack of acquisition and retention of the same task by passive species. Alternatively, frogs and toads can be trained against their natural preferences in passive avoidance paradigms. We have trained toads to avoid dark areas that they normally actively seek. Within $10 \mathrm{~min}$, close to $90 \%$ of the examined toads entered the dark areas and were used in this study. Also, other experiments, in which training against natural preference was used, including the righting response (Harvey, Ellis, \& Tate, 1976) or avoidance of an air current (the senior author's personal observation), were also successful.

Despite several successful applications of the above strategies, biological constraints on learning cast serious doubts on the prospects for cross-species comparisons in Amphibia. No workable learning situations are to be expected to eliminate totally interspecies differences in task-related activity. A possible solution to this problem could be provided by the use of indices of learning that are independent of activity variables. Of course, this approach is applicable only when at least a small amount of response is evident (Anderson \& Miles, 1966).

Even in those studies that used amphibians and in which clear evidence of learning was demonstrated, many anomalies in the learning trends were found (e.g., Boice, 1970). At this stage of the research on learning in anura, there is no justification for speculation about the exact form of learning curves or for the application of advanced mathematical analysis.

As in most studies of memory in amphibians, we used savings or reinforced retention. A comparison of the performance of the toad during the first and second training periods provided a more sensitive indicator of retention than did a nonshock testing trial. Miller and Berk (1976) reached similar conclusions in their study on avoidance of dark background in Xenopus laevis.

The main result of the few studies of memory in amphibians indicate the variability of retention. Toads and frogs can retain different acquired preferences for shapes, position, and background color for different intervals of time, ranging from hours, days, and weeks to several months (Brower \& Brower, 1962; Eibel-Eibesfeldt, 1952; Miller \& Berk, 1977; Miller et al., 1974; Parris, 1963; Yerkes, 1903). Presumably, the maximal retention interval is influenced by the relevance of the acquired behavior to the animal. Toads showed weak retention of a right-left position preference in a T-maze (Greding, 1971) after a 24-h interval, but retained perfectly the avoidance of bees for a period of at least two weeks (Cott, 1936). The relatively short retention interval $(24 \mathrm{~h})$ in our experiments could be due either to the lack of relevance of the acquired behavior or to its being contrary to the natural dark preference of this toad. A different acquired response, one of a more neutral character, might have a longer retention interval in these toads.

The training procedure we have used fulfills the requirement for the analysis of learning processes in 
that it is fully automatic, without requiring manual manipulation of the subject, and is controlled for pseudoconditioning and changes in sensitivity. We have used this technique successfully for a study of the effects of $\alpha$-MSH on acquisition and retention of dark avoidance in Xenopus laevis. It is hoped that this training procedure will provide a tool for scientists of diverse disciplines interested in learning and memory processes in Amphibia.

\section{REFERENCES}

Anderson, R. A., \& Miles, R. C. Correspondence between "spontaneous" activity and learning. Canadian Journal of Psychology, 1966, 20, 273-279.

BoICE, R. Avoidance learning in active and passive frogs and toads. Journal of Comparative and Physiological Psychology, $1970,70,154-156$.

Boice, R., Quanty, C. B., \& Williams, R. C. Competition and possible dominance in turtles, toads, and frogs. Journal of Comparative and Physiological Psychology, 1974, 86, 1116-1131.

Brower, L. P., Brower, J. V. Z. Experimental studies of mimicry. 6: The reaction of toads (Bufo terrestris) to honeybees (Apis mellifera) and their dronefly mimics (Eristalis vinetorum). American Naturalist, 1962, 96, 297-307.

Chu, P. K., \& McCAIn, G. Discrimination learning and extinction in toads. Psychonomic Science, 1969, 14, 14-15.

CoтT, H. B. The effectiveness of protective adaptations in the hive-bee illustrated by experiments on the feeding reactions, habit formation and memory of the common toad (Bufo bufo bufo). Proceedings of the Zoological Society (London), 1936, 111-133.

Crawford, F, T., \& Longdon, J. W. Escape and avoidance responding in the toad. Psychonomic Science, 1966, 6, 115-116.

Eibel-EibesfeldT, I. Nahrungserwerb und Beuteschema der Erdkrote (Bufo bufo L.). Behaviour, 1952, 4, 1-35.

Elsdale, T. R., Gurdon, J. R., \& Fischberg, M. A description of the technique for nuclear transplantation in Xenopus laevis. Journal of Embryology \& Experimental Morphology, 1960, 8, 437-444.
Greding, E. J. Comparative rates of learning in frogs (Ranidae) and toads (Bufonidae). Caribbean Journal of Science, 1971, 11, 203-208.

Harvey, C. B., Ellis, C., \& Tate, M. Inhibition of the righting reflex in the common bullfrog Rana catesbiana employing an operant avoidance procedure. Bulletin of the Psychonomic Society, 1976, 7, 57-58.

Haubrich, R. Comparisons between aggressive behavior and learning rate in the South African clawed frog, Xenopus laevis Daudin. Journal of the Scientific Laboratories, Denison University, 1966, 47, 55-68.

Hershkowitz, M., Segal, M., \& Samuel, D. The acquisition of dark avoidance by transplantation of the forebrain of trained newts (Pheurodeles waltl walt). Brain Research, 1972, 48, 366-369.

MCGILL, T. E. Response of the leopard frog to electric shock in an escape learning situation. Journal of Comparative and Physiological Psychology, 1960, 53, 231-238.

Miller, R. R., Berk, A. M., \& Springer, A. D. Acquisition and retention of active avoidance in Xenopus laevis. Bulletin of the Psychonomic Society, 1974, 3, 139-141.

Miller, R. R., \& Berk, A. M. Retention over metamorphosis in the African claw toed frog. Journal of Experimental Psychology: Animal Behavior Processes, 1977, 3, 343-356.

Parris, J. R. Visual discrimination in the toad. Quarterly Journal of Experimental Psychology, 1963, 15, 13-21.

Rosenkoetter, J., \& Boice, R. Earthworm pheromones and T-maze performance. Journal of Comparative and Physiological Psychology, 1975, 88, 904-910.

Thompson, P. A., \& Boice, R. Attempts to train frogs: Review and experiments. Journal of Biological Psychology, 1975, 17, 3-13.

Thorpe, W. H. Learning and instinct in animals. Cambridge: Harvard University Press, 1963.

Williams, J. T. A test for dominance of cues during maze learning by toads. Psychonomic Science, 1967, 9, 259-260.

YeRKES, R. M. The instincts, habits and reactions of the frogs. Harvard Psychological Studies, 1903, 1, 579.597.

(Received for publication January 21, 1980; revision accepted May 27, 1980.) 